\title{
ESTRUCTURAS NARRATIVAS AMBIENTALES EN EL CRISTIANISMO ORTODOXO (Primera parte)
}

\author{
FELIPE CÁRDENAS TÁMARA \\ UNIVERSIDAD DE LA SABANA. Colombia
}

Resumen: El objetivo del artículo es identificar las principales estructuras narrativas en el discurso ambiental que el Patriarca Bartolomé viene desarrollando desde el año de 1989. El concepto de estructura narrativa, específicamente se estudia en relación con la dimensión ambiental.

Palabras clave: Teología ortodoxa, crisis ambiental, Patriarca Bartolomé, narrativa, cristianismo ortodoxo.

\section{ENVIRONMENTAL NARRATIVE STRUCTURES IN THE ORTHODOX CHRISTIANITY (FIRST PART)}

\begin{abstract}
The aim of the article is to identify the principal narrative structures in the discourse that Patriarch Bartholomew is developing since the year 1989. The concept of narrative structure, specifically is studied in relation to the environmental dimension.
\end{abstract}

Keywords: Orthodox theology, environmental crisis, Patriarch Bartholomew, narrative, Orthodox Christianity.

Recibido: 17.03.2016 - Aceptado: 30.05.2016

Correspondencia: Felipe Cárdenas Támara

Email: felipe.cardenas@unisabana.edu.co

Dr. en Antropología, Magna cum Laudem en Antropología, Bircham International University. Magister en Desarrollo Rural, PUJ; Antropólogo, Universidad de los Andes,

Colombia. Homeópata titulado, British Institute of Homeopathy Director del grupo de investigación Sociopolítica, cultura y ambiente. Director de la maestría en Educación de la Universidad de La Sabana. Calle 10A no. 4-81, Chía, Colombia. 
El autor agradece las correcciones de estilo de la psicóloga Camila Cárdenas Cuéllar, graduada de la Universidad de La Sabana.

\section{Introducción.}

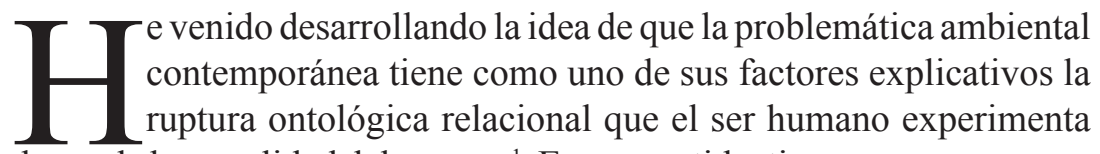
con los planos de la sacralidad del $\operatorname{cosmos}^{1}$. En ese sentido, tiene que reconocerse que el llamado problema ecológico no está exclusivamente relacionado con dinámicas ecosistémicas o biológicas, aun cuando se reconozca en los denominados problemas ambientales capas emergentes que son claramente observables en las dinámicas de los ecosistemas planetarios y en la interacción de ellos con sistemas culturales. Se ha afirmado que una de las raíces de la problemática ambiental se explica a causa del modo de ser o experiencia de orden que la modernidad impuso sobre la de pueblos antiguos, sociedades premodernas occidentales y no-occidentales, modos de producción campesinos y el modo de producción feudal. La crisis ambiental de la civilización occidental está directamente relacionada con un problema que excede y va más allá de un entendimiento centrado en lecturas de orden tecno-ambientales y tecnoeconómicas; en efecto, la problemática referida no puede ser comprendida sin referencias a concepciones del mundo y a sus efectos sobre los territorios. Es decir, los problemas ambientales contemporáneos son la expresión de complejas interacciones mentales que a su vez están condicionados por factores culturales, económicos y ambientales. ${ }^{2}$

1 Véase autor, Cárdenas, F. (2002). Antropología y ambiente: enfoques para una comprensión de la relación ecosistema-cultura. Bogotá: Javergraf; Cárdenas, F. (2006). "Vida, ambiente y percepción. Breve aproximación a los modelos de interpretación ambiental". En: Revista Ideas ambientales. Edición Número 2. Manizales: Universidad Nacional de Colombia; Cárdenas, F. (2007). "Los silenciamientos de la ciencia ambiental. Una reflexión crítica sobre estructuras de opresión", Nómadas. Revista Crítica de Ciencias Sociales y Jurídicas. 16, JulioDiciembre.Madrid: Universidad Complutense; Cárdenas, F. (2008). "Crisis ambiental y cristianismo". Teología y vida., Pontificia Universidad Católica de Chile-Facultad de Teología, vol. 49, no. 4, pp. 771-797; Cárdenas, F. (2015ª) "Categorías y códigos discursivos del cristianismo en su proceso de adaptación humana a la crisis ambiental". En: La sacralidad de la vida en una Tierra habitable para todos. Universidad Popular del Estado de Puebla-México.

$2 \quad$ Véase Cárdenas, F. (2016). "El signo paisaje cultural desde los horizontes de la antropología semiótica". AIBR, Revista de Antropología Iberoamericana, Madrid: 
En el siguiente artículo se presentan las principales estructuras narrativas referidas a la visión y concepción ambiental que se desprende del discurso del Patriarca Ecuménico de Constantinopla Su Santidad Bartolomé, líder religioso del cristianismo ortodoxo. Los textos que se analizan se entienden a la luz de la generación de significaciones ambientales con contenidos noéticos, referidos al despliegue espiritual de la persona y la comunidad. Considero, desde una noción pragmaticista, apoyada en lecturas recientes de los desarrollos teóricos de la obra Charles Sanders Peirce, que la institucionalidad religiosa y sus símbolos, están en capacidad de generar impactos físicos, ya sea positivos o negativos en la configuración de los paisajes y la geografía. ${ }^{3}$

El proceso de análisis consta del estudio de la totalidad de los pronunciamientos del Patriarca Bartolomé en sus referencias al tema ambiental desde el año de 1989. En total se han analizado y categorizado 140 discursos que deben entenderse de manera relacional y en función de prácticas sociales y culturales, cuyos correlatos expresan complejas dinámicas que superan nuestra propia capacidad de aprensión de la realidad y de lo real, dado su anclaje en narrativas apofáticas vinculadas a la expresión de las llamadas teologías negativas. Estas narrativas o teologías reconocen las limitaciones del lenguaje humano para expresar y captar el sentido pleno de la realidad divina, y están fundamentalmente orientadas a establecer las vías para la unión con Dios por parte de los creyentes desde la fundamentación de la experiencia eclesial. ${ }^{4} \mathrm{El}$ trabajo que se presenta sigue las indicaciones de grandes maestros de la semiótica que afirman la importancia de entender las dinámicas culturales, cuyo correlato se expresa en procesos de análisis semióticos complejos, no reducibles a expresiones meramente psicológicas centradas en un simple análisis textual sin ninguna referencia al mundo de las prácticas sociales ${ }^{5}$.

AIBR, 11 (01). Pp. 105-129.

$3 \quad$ Ibid.,pp. 105-129; Strand, T. (2013). Peirce's Rhetorical Turn. Conceptualizing education as semiosis. Educational Philosophy and Theory. Vol. 45, No. 1: 789-803.

4 Véase Felmy, K. (2002). Teología ortodoxa actual. Salamanca: Sígueme; Lossky, V. (1982). Teología mistica de la Iglesia de oriente. Barcelona: Herder; Nesteruk, A. (2003). Light from the East. Theology, Science, and the Eastern Orthodox Tradition. Minneapolis: Fortress press.

5 Véase Saussure, F. (2005). Curso de lingüistica general. Buenos Aires: Losada; Peirce, C. (1978). Lecciones sobre el pragmatismo. Buenos Aires: Editorial Aguilar; Barthes, R. (1990). La aventura semiológica. Barcelona: Paidós; Greimas, A.J. (1976). Semántica estructural, Investigación metodológica. Madrid: Gredos; Eco, H. (1996). Seis paseos por los bosques narrativos. Barcelona: Lumen; Verón, E. (1987). La semiosis social. Fragmentos de una teoría de la discursividad. Barcelona: Gedisa. 


\section{Consideraciones teóricas del problema sobre las llamadas estructuras narrativas}

Los estudios de Reynoso sobre antropología cognitiva afirman cómo el "principio de la economía cognitiva asume que el sistema categorial está diseñado de tal modo que obtiene el máximo de información acerca del medio empleando el mínimo de recursos cognitivos" ". Nuestra mente no está interesada en exploraciones exhaustivas ni puede, por mucho que lo intente, explorar en su totalidad todos los planos exteriores de la realidad o interiores de su propia mente. Reynoso, citando una serie de estudios transculturales afirma cómo estos han demostrado, "que las categorías naturales cognitivas no son construcciones arbitrarias que las comunidades o los sujetos elaboran a su antojo, sino que por el contrario mantienen un alto grado de correspondencia con la estructura correlacional objetiva del mundo"7. El universo perceptivo, en sus discontinuidades y complejos de atributos, señala Reynoso, con base en una cita al trabajo de Eleanor Rosch (1978, Principles of categorization), estructura y organiza la memoria semántica en su propiedades estructurantes y organizativas $^{8}$. En otras palabras, la afectación es doble: la memoria semántica refleja el universo perceptivo y el universo perceptivo está a su vez condicionado por los contenidos y expresiones semánticos que estructuran la mente humana en el contexto de un horizonte transcultural que, con base en estructuras cognitivas universales, dan expresión a los elementos nutricios particulares que vienen del ambiente/naturaleza así como de las relaciones internas que establece la mente.

El mundo que creemos conocer es tan solo uno de los posibles mundos. Lo cierto es que la cultura configura y genera convergencias entre los individuos, pero cada individuo establece conexiones en un número diferenciado de modos, que a su vez están condicionados a los repertorios fijados por las convenciones culturales y las "leyes artificiales". Esta últimas se reproducen mediante los mecanismos de la herencia social y de los procesos de reproducción marcados por la tradición y los devenires históricos que fijan institucionalmente las semánticas del campo de creencias, cuyos correlatos operan mediante la exclusión de otras creencias, por similares que sean.

A diferencia de otros animales, los seres humanos somos únicos en el sentido de que estamos ligados a universos de intencionalidad, discursividad y metadiscursividad, universos que proyectan planos de construcción de procesos

$6 \quad$ Véase Reynoso, C. (1998). Corrientes en antropología contemporánea. Buenos Aires: Editorial Biblos, 67.

$7 \quad$ Ibid., 67.

8 Ibid., 68. 
extras-somáticos que, a diferencia de otras formas de vida avanzada, dejan huella en el territorio mediante anclajes simbólicos y signicos que refieren complejas y peculiares estructuras somáticas y extrasomáticas (la cultura). La noción de intencionalidad está estrechamente ligada a la percepción, representaciones, concepciones e imaginarios que tenemos de los territorios, de los ecosistemas, de la realidad. Igualmente sujeta, está la intencionalidad a la conducta y a las acciones que generamos en los territorios. Esas relaciones entre el mundo humano y no-humano generan procesos de afectación mutua. Nuestros mundos, vinculados a los universos mencionados, están marcados por la presencia de ontologías diversas en la medida en que tienen significados, valores y normas, que generan pautas de conducta que se expresan materialmente como paisajes culturales ${ }^{9}$. Esas ontologías, entendidas como la experiencia de orden que cada cultura mantiene con la realidad, le pueden otorgar diversas concepciones a la realidad en cuanto a la relación que establecen los ecosistemas y las culturas humanas. Cierto es que hay culturas únicas, algunas de ellas desaparecidas o en proceso de extinción, y cuya experiencia ontológica, expresa apropiaciones del sentido de lo real y la realidad que no tiene ningún correlato con nuestra experiencia de orden. Consecuentemente por muy precisa que sea nuestra labor de interpretación de sus campos de significación, siempre nos encontraremos con la incapacidad de lograr una traducción plenamente satisfactoria de todos los contenidos vitales que se expresan en una cultura particular. A lo sumo podremos identificar los objetos materiales y las formas de parentesco que acompañaron su existencia, pero el sentido pleno de sus mundos escapará de nuestra explicación.

Lo anterior se ejemplifica con la siguiente tabla temática, que da cuenta de los diferentes contextos históricos y socio-culturales vividos en el marco de la proyección de las diversas experiencias de orden en las que han estado relacionadas los relatos bíblicos. Véase la tabla 1 como ejemplo de la importancia de la consideración de factores históricos, culturales e interpretativos en lo expresado en el Génesis 1,28 que afirma: $<<$ Dios los bendijo, diciéndoles: Sean fecundos y multiplíquense. Llenen la tierra y sométanla. Tengan autoridad sobre los peces del mar, sobre las aves del cielo y sobre todo ser viviente que se mueve sobre la tierra $>>$.

$9 \quad$ Cárdenas, F. (2016). "El signo paisaje cultural desde los horizontes de la antropología semiótica". AIBR, Revista de Antropología Iberoamericana, Madrid: AIBR, 11 (01). Pp. 105-129. 
FELIPE CÁRDENAS TÁMARA: Estructuras narrativas ambientales en el...

Tabla 1. Contextos históricos y culturales y su impacto ambiental a la luz del Génesis 1,28.

\begin{tabular}{|c|c|c|c|c|c|}
\hline $\begin{array}{l}\text { Período } \\
\text { histórico }\end{array}$ & $\begin{array}{c}\text { Significado } \\
\text { hermenéutico }\end{array}$ & $\begin{array}{c}\text { Modo de } \\
\text { adaptación }\end{array}$ & $\begin{array}{c}\text { Demografía y } \\
\text { parentesco }\end{array}$ & $\begin{array}{c}\text { Modelos } \\
\text { tecnológicos }\end{array}$ & $\begin{array}{c}\text { Efectos } \\
\text { ambientales } \\
\text { negativos. } \\
\text { Escala } \\
\text { mundial }\end{array}$ \\
\hline $\begin{array}{c}\text { Hebreos, } \\
\text { Antiguo } \\
\text { Testamento } \\
\text { (2000-400 } \\
\text { A.C) }\end{array}$ & $\begin{array}{c}\text { Tradición sacerdotal } \\
(\mathrm{P}) \text { : legalista, } \\
\text { predilección por listas } \\
\text { genealógicas. } \\
\text { Tradición yahwista } \\
\text { (J): trabajo y } \\
\text { labranza del suelo, } \\
\text { basada en juglares } \\
\text { y narradores que } \\
\text { trasmiten mensajes } \\
\text { profundos. El hombre } \\
\text { como microcosmos } \\
\text { del mundo// } \\
\text { paralelos con las } \\
\text { concepciones griegas } \\
\text { y de otras tradiciones } \\
\text { cosmológicas que } \\
\text { imponían límites a } \\
\text { la acción del hombre } \\
\text { sobre la naturaleza. }\end{array}$ & $\begin{array}{c}\text { Nomadismo, } \\
\text { pastoralismo, } \\
\text { agricultura, } \\
\text { esclavitud. } \\
\text { Sociedades } \\
\text { pre-estatales, } \\
\text { aparición } \\
\text { de Estados, } \\
\text { vida de aldea, } \\
\text { campesinos. } \\
\text { Mundo rural } \\
\text { dominante }\end{array}$ & $\begin{array}{c}\text { Baja } \\
\text { Fuertes } \\
\text { sistemas de } \\
\text { parentesco }\end{array}$ & $\begin{array}{l}\text { Edad de } \\
\text { Bronce } \\
\text { y Hierro. } \\
\text { Tracción } \\
\text { animal }\end{array}$ & Ninguno \\
\hline $\begin{array}{c}\text { Cristianismo } \\
\text { primitivo- } \\
\text { Patrística } \\
\text { (100 D.C-500 } \\
\text { D.C) }\end{array}$ & $\begin{array}{c}\text { Alegórico } \\
\text { espiritual. Mandato } \\
\text { administrativo, } \\
\text { moral y ético. } \\
\text { Pre-eminencia de la } \\
\text { teología apofática. } \\
\text { La incognoscibilidad } \\
\text { de Dios. Modelo las } \\
\text { obras areopagíticas. } \\
\text { Religión y } \\
\text { espiritualidad } \\
\text { contemplativa del } \\
\text { mundo creado. } \\
\text { Metadiscursividad }\end{array}$ & $\begin{array}{l}\text { Agrícola, } \\
\text { pastoreo. } \\
\text { Esclavismo. }\end{array}$ & $\begin{array}{c}\text { Baja. } \\
\text { Fuertes } \\
\text { sistemas de } \\
\text { parentesco }\end{array}$ & $\begin{array}{l}\text { Edad de } \\
\text { Hierro. } \\
\text { Tracción } \\
\text { animal }\end{array}$ & Ninguno \\
\hline
\end{tabular}


BYZANTION NEA HELLÁS No 36 - 2017: 309 / 330

\begin{tabular}{|c|c|c|c|c|c|}
\hline $\begin{array}{c}\text { Edad } \\
\text { media } \\
(470 \text { D.C- } \\
1500 \text { D.C })\end{array}$ & $\begin{array}{c}\text { Alegórico } \\
\text { espiritual. Mandato } \\
\text { administrativo, moral } \\
\text { y ético. Inicio del } \\
\text { quiebre racionalista } \\
\text { y nominalista. En } \\
\text { el mundo católico } \\
\text { romano una pre- } \\
\text { eminencia de la } \\
\text { teología escolástica } \\
\text { catafática. Modelo } \\
\text { de las vías de santo } \\
\text { Tomás de Aquino. } \\
\text { Racionalismo } \\
\text { religioso. } \\
\text { Discursividad }\end{array}$ & $\begin{array}{l}\text { Agrícola, ciudades, } \\
\text { mercados. } \\
\text { Mercantilismo }\end{array}$ & $\begin{array}{c}\text { Aumento } \\
\text { demográfico. } \\
\text { En términos } \\
\text { absolutos, baja } \\
\text { demografía } \\
\text { mundial. } \\
\text { Sistemas de } \\
\text { parentesco } \\
\text { moderadamente } \\
\text { fuertes. }\end{array}$ & $\begin{array}{c}\text { Nuevas } \\
\text { tecnologías de } \\
\text { navegación, } \\
\text { carreteras, } \\
\text { imprenta, } \\
\text { molienda } \\
\text { de grano y } \\
\text { aserraderos de } \\
\text { madera }\end{array}$ & $\begin{array}{c}\text { Mediana. } \\
\text { Desaparición } \\
\text { de grandes } \\
\text { masas } \\
\text { boscosas en } \\
\text { el continente } \\
\text { europeo. }\end{array}$ \\
\hline $\begin{array}{c}\text { Moderno } \\
(1500- \\
1900)\end{array}$ & $\begin{array}{l}\text { Objetivación de la } \\
\text { naturaleza. Dominio y } \\
\text { explotación material. } \\
\text { Enfrentamientos } \\
\text { entre la reforma y } \\
\text { la contra-reforma. } \\
\text { Sistematización del } \\
\text { procedimiento lógico. } \\
\text { Desnaturalización y } \\
\text { desacralización del } \\
\text { mundo. Colonialismo } \\
\text { iluminista marcado } \\
\text { por la noción de } \\
\text { apertura al mundo, } \\
\text { cuya retórica es de } \\
\text { corte civilizatorio } \\
\text { eurocéntrico. Una } \\
\text { evangelización } \\
\text { con ropaje europeo } \\
\text { y aliada con el } \\
\text { progreso iluminista. } \\
\text { Agnosticismo } \\
\text { kantiano y } \\
\text { modernismo en la } \\
\text { teología occidental. } \\
\text { La teología se hace } \\
\text { faccionalista y } \\
\text { política. }\end{array}$ & $\begin{array}{c}\text { Revolución } \\
\text { científica, } \\
\text { industrialización, } \\
\text { descampesinización. }\end{array}$ & $\begin{array}{c}\text { Importante } \\
\text { incremento } \\
\text { poblacional } \\
\text { Sistemas de } \\
\text { parentesco } \\
\text { debilitados. }\end{array}$ & $\begin{array}{l}\text { Extensión del } \\
\text { uso de carbón, } \\
\text { ferrocarriles, } \\
\text { etnocidios, } \\
\text { colonialismo, } \\
\text { monocultivos, } \\
\text { telégrafos, } \\
\text { electricidad, } \\
\text { fotografía, } \\
\text { minería } \\
\text { industrial }\end{array}$ & Mediano \\
\hline
\end{tabular}




\begin{tabular}{|c|c|c|c|c|c|}
\hline $\begin{array}{c}\text { Contemporáneo } \\
\text { (1900 } \\
\text {-al presente) }\end{array}$ & $\begin{array}{c}\text { Derechos de } \\
\text { la naturaleza. } \\
\text { Reconceptualización } \\
\text { contextualizada por } \\
\text { el ambientalismo: } \\
\text { Ecoteología, } \\
\text { Teología de la Tierra, } \\
\text { Teología ambiental. } \\
\text { El mandato moderno } \\
\text { de dominio y } \\
\text { explotación, sigue } \\
\text { expresándose con } \\
\text { fuerza en algunos } \\
\text { movimientos } \\
\text { cristianos } \\
\text { reformados } \\
\text { conservadores. } \\
\text { Fuerzas centrípetas } \\
\text { en el catolicismo } \\
\text { romano: catolicismo } \\
\text { tradicional, } \\
\text { conservador, } \\
\text { liberal y ultra- } \\
\text { liberal. Presencia } \\
\text { de interpretaciones } \\
\text { bíblicas populares, } \\
\text { carismáticas y } \\
\text { centradas en la } \\
\text { experiencia de Dios. } \\
\text { Retorno a las fuentes } \\
\text { patrísticas en algunos } \\
\text { sectores de la Iglesia } \\
\text { Católica Romana. } \\
\text { Cientifismo. Diálogo } \\
\text { ciencia y Religión. } \\
\text { Alejamiento del } \\
\text { sobre dicho proceso. }\end{array}$ & $\begin{array}{l}\text { Modelo urbano, } \\
\text { industrialización, } \\
\text { capitalismo, } \\
\text { guerras, } \\
\text { genocidio }\end{array}$ & $\begin{array}{c}\text { Incremento } \\
\text { poblacional } \\
\text { e invierno } \\
\text { demográfico. } \\
\text { Sistemas de } \\
\text { parentesco } \\
\text { debilitados y } \\
\text { en transición: } \\
\text { ética del } \\
\text { trabajo } \\
\text { versus ética } \\
\text { contemplativa. }\end{array}$ & $\begin{array}{l}\text { Energía fósil, } \\
\text { nuclear; } \\
\text { presencia } \\
\text { incipiente de } \\
\text { tecnología } \\
\text { sostenibles. } \\
\text { Era digital: } \\
\text { radio, } \\
\text { televisión. } \\
\text { Minería } \\
\text { industrial a } \\
\text { gran escala, } \\
\text { conquista del } \\
\text { espacio, fin } \\
\text { de la era del } \\
\text { petróleo. }\end{array}$ & $\begin{array}{c}\text { Alto. } \\
\text { Cambios } \\
\text { climáticos, } \\
\text { ecocidio } \\
\text { generalizado }\end{array}$ \\
\hline
\end{tabular}

Autor: Elaboración propia 
La tabla anterior señala la importancia de factores históricos y socioculturales en lo referido a las lecturas ambientales que se pueden hacer de los textos bíblicos y de prácticas sociales relacionadas con ellos; y en concreto con la narración de la historia de la creación que se presenta en el libro del Génesis. En la historia de la creación, hasta hace poco los especialistas identificaban dos fuentes distintas: los relatos sacerdotales (P) y los relatos yawhivistas (J). En el conjunto de libros del Antiguo Testamento, específicamente en el Torah de los judíos, los especialistas han identificado cuatro "fuentes", o cuatro "tradiciones" literarias cuyos textos se entrecruzan en su manifestación narrativa (Tradición Yavista, tradición Elohista, Tradición Deuteronomista y el código sacerdotal). Por lo tanto, el relato bíblico no es unívoco en su interpretación. Además, debe tenerse en cuenta que los principales trasmisores culturales estuvieron ligados durante siglos a la tradición oral, cuya memoria semántica se enfrenta siempre a los riesgos de la erosión y muerte cultural del sentido del relato así como a la estructura cultural que le da soporte.

\section{Estructuras narrativas ambientales en el cristianismo ortodoxo.}

Una de las características del sistema de producción discursivo que se viene analizando, dada la tradición de sentido en la que se inserta — la teología mística de la iglesia de oriente-deviene en un importante discurso ambiental, que mantiene una continuidad con el pensamiento de algunos de los padres de la Iglesia, especialmente los de tradición griega o bizantina. Esta condición es sui generis, pues los movimientos ambientales, en algunos casos acentuadamente anti-cristianos o indiferentes a esta tradición, desconocen, ignoran y rechazan la expresión del modo de producción discursivo del cristianismo. Entonces debemos partir del valor que tiene el pensamiento ambiental en la voz discursiva del Patriarca Bartolomé, uno de los líderes ambientales más importantes de los últimos 26 años.

Las tablas que siguen a continuación buscan organizar el material discursivo analizado, estableciendo dos órdenes de realidad diferenciados: el mundo de lo sagrado y el mundo de lo profano. Hemos seguido para la organización de la tabla la distinción sugerida por Niklas Luhmannde inmanencia y trascendencia para denominar los valores específicos de la religión ${ }^{10}$.

Partimos de la idea que el mundo de lo sagrado está constituido por referencias simbólicas que hablan de categorías meta-empíricas. El mundo de lo

$\overline{10}$ Véase Luhmann, N. (2007). La religión de la sociedad. Barcelona: Trotta. 
profano refiere categorías empíricas en su aprensión de la realidad. El discurso del Patriarca no separa la realidad, humana y no humana, física y metafísica, de la manera que nuestro esquema analítico lo hace. Por el contrario, su dinámica narrativa permanentemente está estableciendo relacionamientos con esos dos ámbitos de la realidad: lo profano y lo sagrado. Ahora, la máxima expresión relacional que realiza en el orden del discurso, es un permanente relacionamiento del mundo humano con el mundo no-humano. La premisa fundamento de la narrativa analizada, tiene su anclaje en la tradición de la Iglesia Ortodoxa. Ella señala en sus rasgos esenciales lo que pensara Pável Florenski cuando comentó cómo $<<\ldots$ el deterioro de la naturaleza humana trae consigo el deterioro de toda la creación, mientras que la restauración del hombre devuelve el orden a todas las criaturas...>>11. Esta visión maneja una visión esperanzadora sobre el proceso de reintegración de la creación. El trabajo ascético brinda las promesas para entender que ese proceso está en relación con esta vida. Por lo tanto, las estructuras narrativas tienen un fin práctico: lograr la restauración del sentido de vida en el hombre como condición para la reintegración del orden de la naturaleza.

En síntesis, el proceso de categorización que sigue, tal como señala Carlos Reynoso se expresa a la luz de las siguientes condiciones que marcan el proceso mental tanto del Patriarca, como nuestro propio proceso de clasificación y categorización de la realidad:

"La descripción de la categorización del medio no es independiente del observador, por supuesto, sino que se halla mediatizada por el sistema perceptivo, el que determina cuáles son las propiedades inteligibles y relevantes para el organismo y para el sistema categorial que construye taxonomías con el fin de adecuarse a la estructura percibida" ${ }^{2}$.

11 Florenski, P. (2010). La columna y el fundamento de la Verdad. Salamanca: Ediciones Sígueme, p. 255.

12 Reynoso, C. (1998). Corrientes en antropología contemporánea. Buenos Aires: Editorial Biblos, p. 68. 
Tabla 2. Principales estructuras narrativas. Ámbito de lo sagrado o plano de lo trascendente

\begin{tabular}{|c|c|c|c|c|}
\hline \multicolumn{5}{|c|}{ Principales estructuras narrativas } \\
\hline \multirow{5}{*}{$\begin{array}{l}\text { Ámbito de lo } \\
\text { sagrado/principio o } \\
\text { plano trascendente }\end{array}$} & Categoría & $\begin{array}{l}\text { Definición / } \\
\text { expresión }\end{array}$ & \# Fundamentado & Peso y Densidad \\
\hline & Dogma referencial & $\begin{array}{l}\text { Se refiere a los } \\
\text { textos referenciales, } \\
\text { como la Biblia, } \\
\text { la patrística y } \\
\text { documentos } \\
\text { posiciones de la } \\
\text { tradición de la } \\
\text { Iglesia de Oriente } \\
\text { que le dan un } \\
\text { sello particular a } \\
\text { la comprensión } \\
\text { del problema } \\
\text { ambiental. }\end{array}$ & 195 & 14 \\
\hline & $\begin{array}{c}\text { Concepción } \\
\text { ambiental y visión } \\
\text { de mundo }\end{array}$ & $\begin{array}{l}\text { Contenidos de la } \\
\text { narrativa cristiana } \\
\text { en su visión y } \\
\text { concepción de } \\
\text { mundo ambiental, }\end{array}$ & 207 & 10 \\
\hline & $\begin{array}{l}\text { Particularidad del } \\
\text { dogma referencial }\end{array}$ & $\begin{array}{c}\text { Experiencia } \\
\text { particular y singular } \\
\text { de la Iglesia de } \\
\text { Oriente en cuanto } \\
\text { a su capacidad de } \\
\text { comprensión de } \\
\text { la problemática } \\
\text { ambiental. }\end{array}$ & 123 & 9 \\
\hline & Patrística & $\begin{array}{l}\text { Uso de fuentes } \\
\text { patrísticas o } \\
\text { referidas a } \\
\text { santos hombres } \\
\text { de la tradición } \\
\text { cristiana de los } \\
\text { primeros siglos del } \\
\text { cristianismo. }\end{array}$ & 67 & 6 \\
\hline
\end{tabular}


FELIPE CÁRDENAS TÁMARA: Estructuras narrativas ambientales en el...

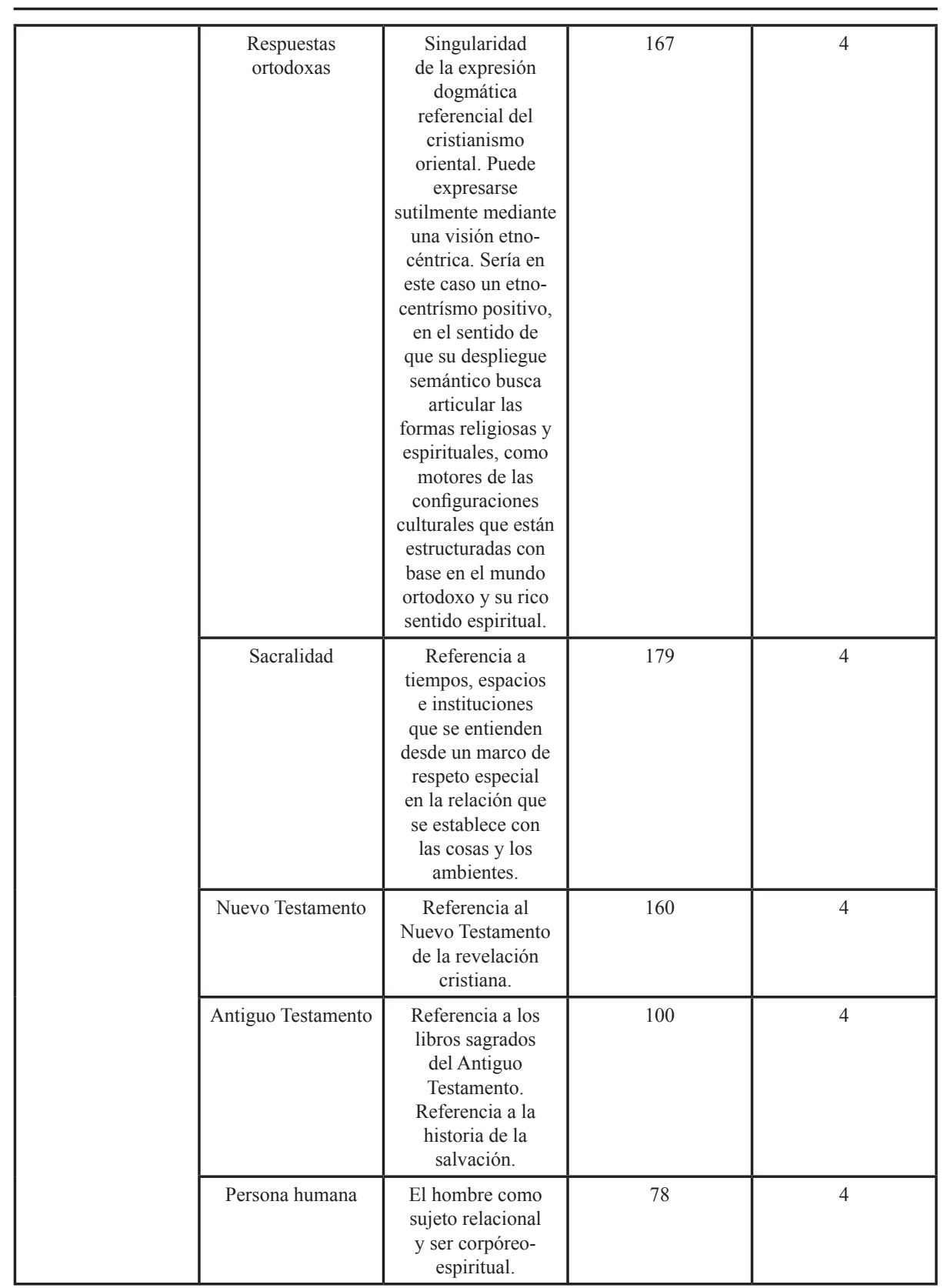


BYZANTION NEA HELLÁS No 36 - 2017: 309 / 330

\begin{tabular}{|c|c|c|c|}
\hline $\begin{array}{l}\text { Argumento } \\
\text { ontológico }\end{array}$ & $\begin{array}{l}\text { Semántica dada } \\
\text { por nociones de } \\
\text { orden trascendente } \\
\text { como indicación de } \\
\text { la dinámica de la } \\
\text { realidad. }\end{array}$ & 87 & 3 \\
\hline Iglesia & $\begin{array}{c}\text { Referencia a } \\
\text { la importancia } \\
\text { eclesial en el } \\
\text { marco operador del } \\
\text { discurso ambiental. }\end{array}$ & 154 & 3 \\
\hline Papel de la religión & $\begin{array}{l}\text { Explícita mención } \\
\text { a la importancia } \\
\text { de la religión } \\
\text { para el mundo } \\
\text { contemporáneo por } \\
\text { su importante papel } \\
\text { en el despliegue } \\
\text { de potenciales y } \\
\text { mensajes valiosos. }\end{array}$ & 72 & 3 \\
\hline Eucaristía y liturgia & $\begin{array}{c}\text { Ritual de } \\
\text { consagración del } \\
\text { misterio de la } \\
\text { presencia de Jesús } \\
\text { en el sacrificio } \\
\text { eucarístico. }\end{array}$ & 56 & 2 \\
\hline $\begin{array}{c}\text { Ascesis y } \\
\text { monasticismo }\end{array}$ & $\begin{array}{c}\text { Referencia a la } \\
\text { vida monástica } \\
\text { como modelo de } \\
\text { vida anclado a un } \\
\text { territorio particular, } \\
\text { que por ello es } \\
\text { transformado de } \\
\text { manera ecológica } \\
\text { gracias a la acción } \\
\text { de los monjes o } \\
\text { monjas. }\end{array}$ & 41 & 2 \\
\hline
\end{tabular}

Fuente: Autor 
FELIPE CÁRDENAS TÁMARA: Estructuras narrativas ambientales en el...

Tabla 3. Principales estructuras narrativas. Ámbito de lo profano o inmanente

\begin{tabular}{|c|c|c|c|c|}
\hline \multicolumn{5}{|c|}{ Principales estructuras narrativas } \\
\hline \multirow{4}{*}{$\begin{array}{c}\text { Ámbito de lo } \\
\text { profano / } \\
\text { empiricidad }\end{array}$} & Categoría & Definición & \# Fundamentado & Peso y Densidad \\
\hline & $\begin{array}{l}\text { Remedios y } \\
\text { soluciones }\end{array}$ & $\begin{array}{c}\text { Habiendo definido } \\
\text { la naturaleza } \\
\text { del problema, } \\
\text { se expresan las } \\
\text { soluciones al } \\
\text { mismo. Será } \\
\text { clave la noción } \\
\text { de ascesis desde } \\
\text { el cristianismo. } \\
\text { Fusionado de: } \\
\text { Referencia } \\
\text { litúrgica (2014-10- } \\
\text { 08T15:48:11)*** } \\
\text { Se realiza una } \\
\text { mención al valor y } \\
\text { papel de la liturgia } \\
\text { en la construcción } \\
\text { del signo ambiental. }\end{array}$ & 202 & 5 \\
\hline & $\begin{array}{c}\text { Denuncia, conflicto } \\
\text { y crítica }\end{array}$ & $\begin{array}{c}\text { Reconocimiento } \\
\text { del conflicto y } \\
\text { del antagonismo } \\
\text { en el plano de } \\
\text { los problemas } \\
\text { ambientales, } \\
\text { la unión de los } \\
\text { cristianos y los } \\
\text { problemas de } \\
\text { comunicación } \\
\text { humana. Presencia } \\
\text { del mal y } \\
\text { corrupción humana. }\end{array}$ & 293 & 3 \\
\hline & Campo académico & $\begin{array}{c}\text { Auditorio y } \\
\text { receptores } \\
\text { cuyo campo de } \\
\text { relaciones sociales } \\
\text { están definidas por } \\
\text { la presencia de } \\
\text { espacios temáticos } \\
\text { marcados por la } \\
\text { vida de la academia. }\end{array}$ & 173 & 1 \\
\hline
\end{tabular}


BYZANTION NEA HELLÁS No 36 - 2017: 309 / 330

\begin{tabular}{|c|c|c|c|}
\hline Canales de diálogo & $\begin{array}{c}\text { Apertura dialógica, } \\
\text { dada por un } \\
\text { mensaje que } \\
\text { establece puentes } \\
\text { de comunicación } \\
\text { para la superación } \\
\text { de impedimentos } \\
\text { marcados por } \\
\text { diferencias } \\
\text { culturales, } \\
\text { religiosas o } \\
\text { políticas. }\end{array}$ & 167 & 4 \\
\hline Causalidad & $\begin{array}{c}\text { Factores originarios } \\
\text { del problema, cuya } \\
\text { expresión puede } \\
\text { ser de orden moral, } \\
\text { ética o cultural. Las } \\
\text { causas pueden ser } \\
\text { explicadas desde } \\
\text { una interpretación } \\
\text { científica o de orden } \\
\text { noético. }\end{array}$ & 126 & 4 \\
\hline $\begin{array}{l}\text { Problemas } \\
\text { prioritarios }\end{array}$ & $\begin{array}{c}\text { Expresión física, } \\
\text { moral, ambiental } \\
\text { o social de la } \\
\text { crisis ambiental. } \\
\text { Se puede estar } \\
\text { hablando de los } \\
\text { desastres causados } \\
\text { por el ser humano } \\
\text { y sus modos } \\
\text { de producción. } \\
\text { Hay expresiones } \\
\text { emergentes } \\
\text { marcadas por el } \\
\text { odio, el fanatismo, } \\
\text { la violencia y la } \\
\text { corrupción. }\end{array}$ & 185 & 2 \\
\hline $\begin{array}{c}\text { Argumento ciencias } \\
\text { naturales }\end{array}$ & $\begin{array}{c}\text { Enunciado } \\
\text { basado en datos } \\
\text { proporcionados por } \\
\text { las ciencias de la } \\
\text { Tierra y las ciencias } \\
\text { naturales. }\end{array}$ & 137 & 2 \\
\hline Territorialidad & $\begin{array}{l}\text { Identificación } \\
\text { y referencia } \\
\text { a espacios } \\
\text { geográficos, } \\
\text { lugar en la } \\
\text { caracterización } \\
\text { del problema } \\
\text { ambiental. }\end{array}$ & 149 & 1 \\
\hline
\end{tabular}


FELIPE CÁRDENAS TÁMARA: Estructuras narrativas ambientales en el...

\begin{tabular}{|c|c|c|c|}
\hline $\begin{array}{c}\text { Principios morales } \\
\text { y éticos }\end{array}$ & $\begin{array}{l}\text { Valores y axiomas } \\
\text { anclados en ejes } \\
\text { estructurantes para } \\
\text { condicionar el } \\
\text { comportamiento } \\
\text { humano. Se } \\
\text { destacan ejes } \\
\text { de principios; } \\
\text { se señalan } \\
\text { rutas y anclajes } \\
\text { fundamentales } \\
\text { del pensamiento } \\
\text { ambiental de } \\
\text { referencia. }\end{array}$ & 148 & 1 \\
\hline Acción ambiental & $\begin{array}{c}\text { Procesos de orden } \\
\text { social, cultural, } \\
\text { económico y } \\
\text { tecnológico, } \\
\text { destinado a dar } \\
\text { soluciones a la } \\
\text { problemática } \\
\text { ambiental. Puede } \\
\text { estar referido } \\
\text { al campo de la } \\
\text { educación y la } \\
\text { concientización. }\end{array}$ & 110 & 1 \\
\hline Pragmatismo & $\begin{array}{l}\text { Acciones que se } \\
\text { desencadenan por } \\
\text { la acción de los } \\
\text { modelos mentales e } \\
\text { institucionales. }\end{array}$ & 106 & 2 \\
\hline Campo político & $\begin{array}{l}\text { Auditorio y } \\
\text { receptores } \\
\text { cuyo campo de } \\
\text { relaciones sociales } \\
\text { están definidas } \\
\text { por la presencia } \\
\text { temática actores } \\
\text { pertenecientes al } \\
\text { mundo político. }\end{array}$ & 95 & 1 \\
\hline $\begin{array}{l}\text { Anclaje filosofía } \\
\text { clásica }\end{array}$ & $\begin{array}{c}\text { Diálogo con } \\
\text { el aporte de la } \\
\text { filosofía clásica } \\
\text { del mundo griego. } \\
\text { Los soportes } \\
\text { conceptuales } \\
\text { apoyan el desarrollo } \\
\text { de la narrativa } \\
\text { ambiental. }\end{array}$ & 41 & 3 \\
\hline
\end{tabular}


BYZANTION NEA HELLÁS No 36 - 2017: 309 / 330

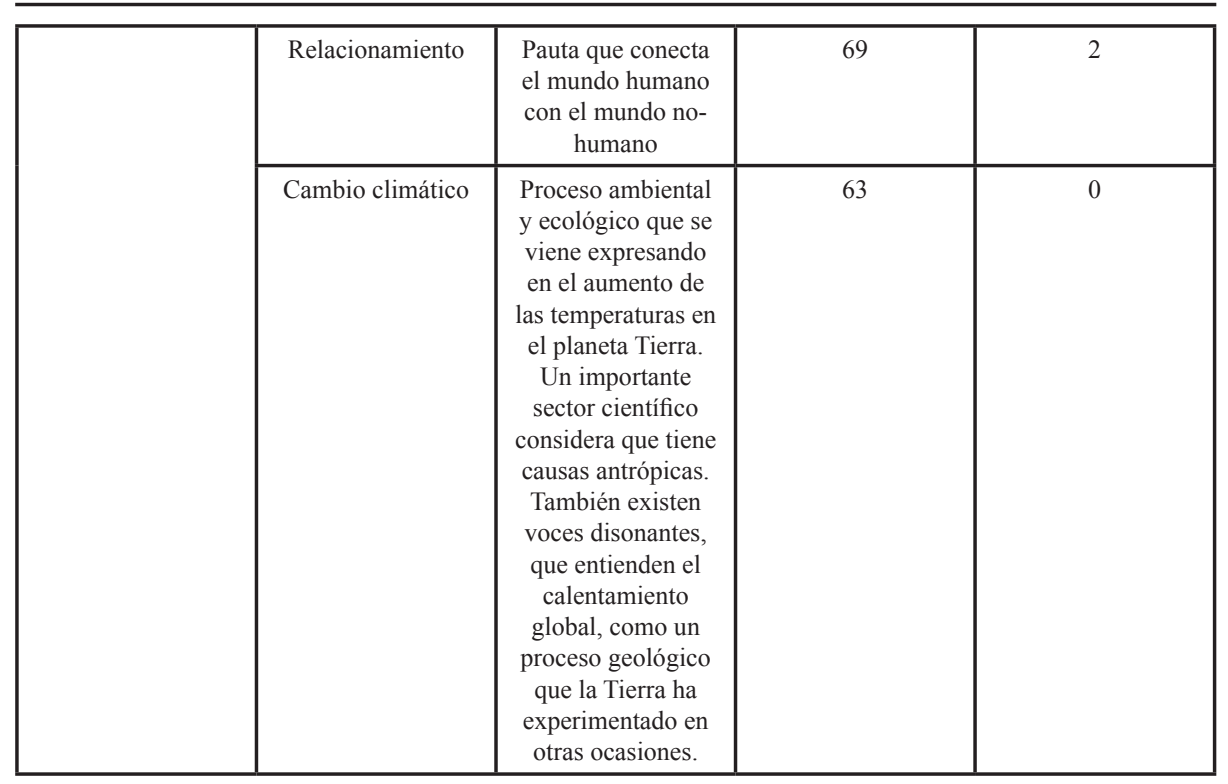

Fuente: Autor.

\section{Discusión}

La crisis ambiental contemporánea implica abrir espacios para la consolidación de un paradigma ambiental que busque integrar los conocimientos de la ciencia y tenga la posibilidad de valorar las formas tradicionales de ver la realidad, insertas aún en sistemas de representación como los existentes en el campo de la religión. La narrativa observada y analizada nos permite ver la importancia del reconocimiento de la articulación entre Verdades religiosas y verdades científicas. La expresión de la estructura narrativa analizada, se expresa desde una ontología diferente a la de la ciencia. Se puede afirmar que ambas narrativas son complementarias y enriquecen nuestra comprensión de la realidad. La narrativa religiosa establece unos contenidos y sentidos que no constituyen la base central de la indagación científica, pero sí expande los sentidos y el horizonte de las verdades científicas. La superación de la problemática ambiental implica pensar y repensar la articulación de los fenómenos socioculturales y su relación interactiva con realidades ecosistémicas, biológicas y cósmicas. Los estudios sobre percepción del ambiente y sus concepciones, implican el descubrimiento de las pautas de ver, pensar y de actuar en la realidad. Dichos estudios hacen parte del conocimiento y de la herencia social de los sistemas culturales, que 
nos brindan en el marco de sus respuestas adaptativas (inadaptativas), muchas claves y puentes para la superación de la problemática ambiental que viven los sistemas culturales contemporáneos.

Las relaciones entre los sistemas culturales y los ecosistemas se expresan de manera cognitiva y material, es decir en la conciencia y en la cultura material. Se torna importante recordar que los ecosistemas para la antropología y la geografía cultural, son narrados como mentefactos, sociofactos o artefactos; es decir, hay fuertes referentes pragmáticos. Esto no quiere decir que los biotopos no existan y que el abordaje tradicional de las ciencias naturales no sea necesario. Sencillamente se enfatiza la importancia de estudiar los ambientes más allá de su mera expresividad biofísica y como si fueran entidades a-históricas. La relación ecosistema - cultura, como cualquier relación en la lógica de la vida es de mutua interdependencia. ${ }^{13}$ Las obras de Gregory Bateson y Claude Leví Strauss, contienen importantes postulados que ayudan a definir y a redefinir conceptos como los de vida, ambiente y percepción; los conceptos en mención son fundamentales en toda la argumentación sobre el tema de las narrativas ambientales ${ }^{14}$. Las ideas de los autores previamente mencionados, nos llevan a preguntarnos cómo es que los seres humanos perciben el mundo y la vida alrededor de ellos. Noción que en palabras de Bateson, ha sido referida como la expresión de una ecología de la mente, ya que según él, percibir el mundo es también percibir la vida, que a su vez es captada por la mente ${ }^{15}$. Como expresión elaborada de una ecología de la mente, el antropólogo Tim Angol, señala cómo en respuesta a dicha pregunta, se tiene que superar y buscar alternativas a la concepción tradicional tan común en el medio antropológico de considerar, en lo referente a la percepción ambiental, el ya trillado argumento que afirma que la naturaleza es una construcción cultural y social, o el producto de capas superpuestas de significancia emic, independientes de una realidad etic dada ${ }^{16}$. En efecto, el replanteamiento de Ingold nos deberá llevar a tener en cuenta los siguientes aspectos que se connotan en el trabajo realizado: Primero, el concepto de ambiente es un término relativo. El ambiente que hemos referido está en

13 Cárdenas, F. (2007). Los silenciamientos de la ciencia ambiental. Una reflexión crítica sobre estructuras de opresión, Nómadas. Revista Crítica de Ciencias Sociales y Jurídicas. Madrid: Universidad Complutense. 16, Julio-Diciembre.

14 Véase Bateson, G. (1982). Una unidad sagrada: pasos ulteriores hacia una ecología de la mente. Barcelona: Gedisa; Levi, Strauss, C. (1971). Mitológicas. Méjico: Fondo de cultura económica.

15 Véase Bateson, G. (1971). Pasos hacia una ecología de la mente. Buenos Aires: Planeta.

16 Véase Ingold, T. (2000). Essays in livelihood and skill. London: Routledge.20. 
función del ser vivo del que hablemos, en este caso la teología bizantina y su particular apropiación de la dimensión ambiental. Con base en triangulaciones realizadas en Etiopia, se ha comprobado que los ambientes y territorios en importantes porciones geográficas marcadas por la experiencia de orden del cristianismo ortodoxo, se explican a la luz de la correlación entre ambiente y organismo ${ }^{17}$. En ese caso el organismo se expresa mediante todo el despliegue institucional de la Iglesia Ortodoxa y su capacidad de afectación de los paisajes biofísicos.Este enunciado nos recuerda el mundo del proceso mental abordado/ profundizado por Gregory Bateson, donde se establece que dicho proceso mental es configurador de la ecología de la vida. Es decir, un ambiente, al que se puede considerar como parte del itinerario personal, existe como mundo, tomando significado para sus actores sociales en un contexto de fluidez, que desarrolla o genera elementos de afectación individual y personal ${ }^{18}$. Es decir, el ambiente/ naturaleza constituye y configura subjetividad. De lo anterior se infiere que los ambientes están en permanente co-evolución y transformación. Los ambientes se configuran bajo la acción de la vida; en ese horizonte, la cultura humana, como parte de la vida, participa en la constitución de los ambientes que pueden considerarse como entidades en permanente construcción y movimiento. La narrativa analizada se expresa desde nuestra consideración, como uno de los desarrollos argumentativos más ricos y profundos en el campo de los discursos ambientales contemporáneos.

\section{Conclusiones}

Estamos ante un discurso contingente e inserto en la ontología del cristianismo oriental; su lógica discursiva no es arbitraria, no pretende incorporar la verdad de su narración mediante imposiciones violentas, jurídicas o esquemas no-dialógicos. La sensibilidad ambiental que se encuentra en los registros narrativos, se complementa con un componente inteligible que desarrolla un gran argumento sobre una base sensible (significante) que

$17 \quad$ Véase Cárdenas, F. (2015b). Christianity and sustainable development: the case of Ethiopia. https://youtu.be/OA5FDCopjRs; Cárdenas, F. (2015c). Ethiopia: sacredland. https://youtu.be/xqMr2ce0FO0; Cárdenas, F. (2015d). Ethiopia sacredland II. https://youtu.be/xqMr2ce0FO0; Cárdenas, F. (2015e). Abune Mathias: Patriarch of Ethiopia https://youtu.be/CNdr8zHbi7I

18 Vése Bateson, G. (1971). Pasos hacia una ecología de la mente. Buenos Aires: Planeta; Bateson, G. (1982). Una unidad sagrada: pasos ulteriores hacia una ecología de la mente. Barcelona: Gedisa. 
estamos capacitados para captar en el lenguaje y percibir cotidiano.El discurso ambiental del Patriarca, vinculado con la rica tradición de la teología bizantina, crea y organiza cadenas de significación, cuya base nuclear es ambiental y cosmopolíticay desde un sello cristiano, dialoga con otras culturas, religiones y tradiciones intelectuales.

Constatamos un discurso de muchas capas, niveles e interpretaciones. La estructura fundamental deriva de la tradición patrística. En efecto, la herencia patrística se establece como el gran argumento de las profundidades y riquezas de la herencia bíblica y del mensaje de Jesús; esta herencia contribuye positiva y constructivamente a comprender los asuntos más críticos de nuestros tiempos. En el horizonte de dicha herencia,se hayan las verdades eclesiales en su contenido pleno. Se destaca enfáticamente en el discurso y la tradición analizada, la importancia de la vida litúrgica y de la eucaristía, como ejes centrales de todo el argumento mito-poético y soteriológico del que dispone la tradición cristiana para la salvación del mundo en su proyección ambiental, política, comunitaria y personal. El núcleo de ese eje podría considerarse como la expresión centrípeta y centrifuga del cristianismo ortodoxo y católico y de la comunidad de creyentes que de la manera más íntima, quiere vivir el mensaje más profundo del evangelio, en una dinámica espacio-temporal que es de orden metadiscursiva y experiencial. El componente litúrgico, es el meta-discurso por excelencia. Su constitución espacio-temporal y discursiva está en capacidad de ponerle límites a la discursividad humana, estableciendo espacios para la contemplación de fenómenos que están más allá de la capacidad perceptiva y conceptual que tiene el ser humano. Los efectos de la meta-discursividad litúrgica, siguiendo la noción de máxima pragmática, tienen la fuerza de generar efectos y cambio de hábitos en los participantes del ritual y de la semiósfera, que constituye los elementos del campo perceptivo y su semántica.

\section{REFERENCIAS BIBLIOGRÁFICAS}

BARTHES, R. (1990). La aventura semiológica. Barcelona: Paidós.

BATESON, G. (1982) Una unidad sagrada: pasos ulteriores hacia una ecología de la mente. Barcelona: Gedisa,

BATESON, G. (1971). Pasos hacia una ecología de la mente. Buenos Aires: Planeta.

CÁRDENAS, F. (2016). "El signo paisaje cultural desde los horizontes de la antropología semiótica". AIBR, Revista de Antropología Iberoamericana, Madrid: AIBR, 11 (01). 
CÁRDENAS, F. (2015ª) "Categorías y códigos discursivos del cristianismo en su proceso de adaptación humana a la crisis ambiental"! En: La sacralidad de la vida en una Tierra habitable para todos. Universidad Popular del Estado de Puebla-México.

CÁRDENAS, F. (2015b). Christianity and sustainable development: the case of Ethiopia. https://youtu.be/OA5FDCopjRs

CÁRDENAS, F. (2015c).Ethiopia: sacred land. https://youtu.be/xqMr2ce0FO0

CÁRDENAS, F. (2015d). Ethiopia sacred land II. https://youtu.be/xqMr2ce0FO0

CÁRDENAS, F. (2015e). Abune Mathias: Patriarch of Ethiopia. https://youtu.be/CNdr8zHbi7I

CÁRDENAS, F. (2014). "Cambio climático y su apropiación en la pastoral católicaortodoxa. El magisterio de Su Santidad Bartolomé, Patriarca Ecuménico de Constantinopla". En: Dialogo Ecuménico. Universidad Pontificia de Salamanca: Centro de Estudios Orientales y Ecuménicos “Juan XXIII”, Tomo 49, N. 154155, págs. 79-96.

CÁRDENAS, F. (2008). “Crisis ambiental y cristianismo". Teología y vida., Pontificia Universidad Católica de Chile-Facultad de Teología, vol. 49, no. 4, pp. 771-797.

CÁRDENAS, F. (2007). "Los silenciamientos de la ciencia ambiental. Una reflexión crítica sobre estructuras de opresión", En: Nómadas. Revista Crítica de Ciencias Sociales y Jurídicas.16, Madrid: Universidad Complutense. .Julio-Diciembre.

CÁRDENAS, F. (2006). "Vida, ambiente y percepción. Breve aproximación a los modelos de interpretación ambiental". En: Revista Ideas ambientales. Edición Número 2. Manizales: Universidad Nacional de Colombia.

CÁRDENAS, F. (2002). Antropología y ambiente: enfoques para una comprensión de la relación ecosistema-cultura. Bogotá: Javergraf.

DUCH, L. (1998). Mito, interpretación y cultura, Barcelona: Herder.

ECO, H. (1996). Seis paseos por los bosques narrativos. Barcelona: Lumen.

FELMY, K. (2002). Teología ortodoxa actual. Salamanca: Sígueme.

FLORENSKI, P. (2010). La columna y el fundamento de la Verdad. Salamanca: Ediciones Sígueme.

GREIMAS, A.J. (1976). Semántica estructural, Investigación metodológica. Madrid: Gredos.

INGOLD, T. (2000). Essays in livelihood and skill.London: Routledge.

LOSSKY, V. (1982). Teología mística de la Iglesia de oriente. Barcelona: Herder.

LEVI, STRAUSS, C. (1971).Mitológicas.Méjico: Fondo de cultura económica.

LUHMANN, N. (2007). La religion de la sociedad. Barcelona: Trotta.

NESTERUK, A. (2003). Light from the East. Theology, Science, and the Eastern Orthodox Tradition. Minneapolis: Fortress press.

SAUSSURE, F. (2005). Curso de lingüistica general.Buenos Aires: Losada. 
STRAND, T. (2013). Peirce's Rhetorical Turn. Conceptualizing education as semiosis. Educational Philosophy and Theory. Vol. 45, No. 1.

PAPA FRANCISCO. (2015). Carta Encíclica Laudato Sí. Sobre el cuidado de la casa Común. Quito: Editorial Paulinas.

PEIRCE, C. (1978). Lecciones sobre el pragmatismo. Buenos Aires: Editorial Aguilar. PERLS, F. (1982).Terapia Gestalt: teoría y práctica.Méjico: Concepto.

REYNOSO, CARLOS. (1998). Corrientes en antropología contemporánea. Buenos Aires: Editorial Biblos.

VERÓN, E. (1987). La semiosis social. Fragmentos de una teoría de la discursividad. Barcelona: Gedisa.

YELLE, R. (2012).Semiotics of religion, Signs of the sacred in History. London: Bloomsbury. 